\title{
Is the buying of loot boxes in videogames a form of gambling or gaming?
}

\author{
Mark D. Griffiths
}

International Gaming Research Unit, Psychology Department

Nottingham Trent University, 50 Shakespeare Street, Nottingham, NG1 4FQ, United Kingdom

Email: mark.griffiths@,ntu.ac.uk

Mark D. Griffiths is Professor of Behavioural Addiction in the Psychology Department at Nottingham Trent University in Nottingham, United Kingdom.

Keywords: Loot boxes; social gambling; virtual assets; in-game purchasing; video game gambling 
"The novelty of [Las Vegas] can bide its true intentions. [Its] seediness might be hard to detect on the surface of many video games, but replace the roulette table with a Candy Crush wheel and the similarities become clearer. Think about how many times you've paid real-life money in a game for the chance to win an item you really wanted. Was it a nice Overwatch skin? Perhaps it was a coveted Hearthstone card. How many times did you not get the item you wanted, then immediately bought in for another chance to bit the big time?" ${ }^{\prime 11}$.

The buying of loot boxes takes place within online videogames and are (in essence) virtual games of chance. Players use real money to buy virtual in-game items and can redeem such items by buying keys to open the boxes where they receive a chance selection of further virtual items. Other types of equivalent in-game virtual assets that can be bought include crates, cases, chests, bundles, and card packs. The virtual items that can be 'won' can comprise basic customization (i.e., cosmetic) options for a player's in-game character (avatar) to in-game assets that can help players progress more effectively in the game (e.g., gameplay improvement items such as weapons, armor ${ }^{[1-3]}$. All players hope that they can win 'rare' items and are often encouraged to spend more money to do so because the chances of winning such items are minimal. Many popular videogames now feature loot boxes (or equivalents) including Overwatch, Middle-earth: Shadow of War, Star Wars Battlefront 2, FIFA Ultimate Team, Mass Effect: Andromeda, Fortress 2, Injustice 2, Lawbreakers, Forza Motorsport 7, and For Honor ${ }^{1,2]}$. In short, all of these require the paying of real money in exchange for a completely random in-game item. In an interview with Eurogamer, psychologist Jamie Madigan said:

"Whenever you open [a loot box], you may get something awesome (or you may get trash). This randomness taps into some of the very fundamental ways our brains work when trying to predict whether or not a good thing will happen. We are particularly excited by unexpected pleasures like a patch of wild berries or an epic skin for our character. This is because our brains are trying to pay attention to and trying to figure out such awesome rewards. But unlike in the real world, these rewards can be completely random (or close enough not to matter) and we can't predict randomness. But the reward system in your brain doesn't know that. Buying [loot boxes] puts them into the same category of packs of Pokémon cards or baseball cards. Unlike gambling in a casino, you're going to get something out of that pack. Maybe just not the thing you wanted" ${ }^{[1]}$.

Although there are many definitions in many disciplines defining gambling, there are a number of common elements that occur in the majority of gambling instances that distinguish 'true' gambling from mere risk-taking ${ }^{[4]}$. These include: (i) the exchange is determined by a future 
event, which at the time of staking money (or something of financial value), the outcome is unknown, (ii) the result is determined (at least partly or wholly) by chance, (iii) the re-allocation of wealth (i.e., the exchange of money [or something of financial value] usually without the introduction of productive work on either side, and (iv) losses incurred can be avoided by simply not taking part in the activity in the first place. Added to this, it could be argued that the money or prize to be won should be of greater financial value than the money staked in the first place. Based on these elements, the buying of loot boxes (or equivalents) would be classed as a form of gambling, as would other activities such as the Treasure Hunter and Squeal of Fortune games within the Runescape videogame ${ }^{[5]}$ and online penny auctions ${ }^{[6]}$.

The UK Gambling Commission's most recent (March 2017) position paper $^{[7]}$ on virtual currencies and social casino gambling noted:

"One commonly used method for players to acquire in-game items is through the purchase of keys from the games publisher to unlock 'crates', 'cases' or 'bundles' which contain an unknown quantity and value of in-game items as a prize. The payment of a stake (key) for the opportunity to win a prize (in-game items) determined (or presented as determined) at random bears a close resemblance, for instance, to the playing of a gaming macbine. Where there are readily accessible opportunities to cash in or exchange those awarded in-game items for money or money's worth those elements of the game are likely to be considered licensable gambling activities [Section 3.17]... Additional consumer protection in the form of gambling regulation, is required in circumstances where players are being incentivised to participate in gambling style activities through the provision of prizes of money or money's worth. Where prizes are successfully restricted for use solely within the game, such in-game features would not be licensable gambling, notwithstanding the elements of expenditure and chance [Section 3.18]".

Consequently, the UK Gambling Commission does not consider loot boxes as a form of gambling because (they claim) the in-game items have no real-life value outside of the game. However, this is not the case because there are many websites that allow players to trade in-game items and/or virtual currency for real money. The Gambling Commission appears to acknowledge this point and claim that the buying of in-game loot boxes (and their equivalents) are not gambling but, if third party sites become involved (by allowing the buying and selling of in-game items), the activity does become a form of gambling. As Hood ${ }^{[1]}$ rightly notes, this appears to be a case of the law struggling to keep pace with technology. There are also issues surrounding age limits and whether games that offer loot boxes (or equivalents) should be restricted to those over the age of 18 years. 
Predictably, those in the videogame industry do not view the buying of loot boxes as gambling either. For instance, Dirk Bosmans (from PEGI [Pan European Game Information], the Europeanbased videogame rating organization) stated in a recent interview with Eurogamer ${ }^{[1]}$ that:

'Loot crates are currently not considered gambling: you always get something when you purchase them, even if it's not what you hoped for. For that reason, a loot crate system does not trigger the gambling content descriptor. If something is considered gambling, it needs to follow a very specific set of legislation, which has all kinds of practical consequences for the company that runs it. Therefore, the games that get a PEGI gambling content descriptor either contain content that simulates what is considered gambling or they contain actual gambling with cash payouts. If PEGI would label something as gambling while it is not considered as such from a legal point of view, it would mostly create confusion. We are always monitoring such developments and mapping consumer complaints. We see a growing need for information about specific features in games and apps (social interaction, data sharing, digital purchases), but the challenge is that such features are rapidly becoming ubiquitous in the market, yet they still come in very different shapes and sizes."

This appears somewhat hardline given that PEGI's descriptor of gambling content is used whenever any videogame "teaches or encourages" gambling. Such a descriptor would arguably cover gambling-like games or activities and the buying of loot boxes is 'gambling-like' at the very least. The same stance has been taken by the Entertainment Software Rating Board (ESRB) which rates videogames in Canada and the $\mathrm{USA}^{[1]}$. A spokesman for the ESRB told Eurogamer ${ }^{[1]}$ that:

"ESRB does not consider [the buying of loot boxes] to be gambling because the player uses real money to pay for and obtain in-game content. The player is always guaranteed to receive something - even if the player doesn't want what is received. Think of it like opening a pack of collectible cards: sometimes you'll get a brand new, rare card, but other times you'll get a pack. full of cards you already have. That said, ESRB does disclose gambling content should it be present in a game via one of two content descriptors: Simulated Gambling (player can gamble without betting or wagering real cash or currency) and Real Gambling (player can gamble, including betting or wagering real cash or currency). Neither of these apply to loot boxes and similar mechanics."

At present, there are a number of countries (mainly in South East Asia, such as China and Japan) who do view the buying of loot boxes as a form of gambling and have incorporated such activities into their gambling regulations ${ }^{[3]}$. However, most countries have either not considered regulating the buying of loot boxes at all, or (like the UK), have ruled that buying loot boxes 
does not currently meet their regulatory definition of gambling. Although there has been little published in academic journals on loot boxes, a number of articles in the trade press have claimed that the buying of loot boxes can be problematic and/or addictive because they are designed using highly similar reward schedules to those used in the design of slot machines ${ }^{[8-11]}$. This is something that I have also pointed out in relation to similar activities to the buying of loot boxes where individuals play for points rather than money ${ }^{[12]}$. Personally, I view the buying of loot boxes as a form of gambling, particularly because the 'prizes' won are (in financial terms) often a lot less than that of the price paid. Obviously, I am out of step in relation to the regulators in my own country, but if third party websites continue to host services where ingame virtual items can be bought and sold, the activity definitely constitutes a form of gambling by almost any definition of gambling currently used in the field of social sciences.

\section{References}

[1] Vic Hood, Are loot boxes gambling? EUROGAMER October 12 (2017) Located at: <http://www.eurogamer.net/articles/2017-10-11-are-loot-boxes-gambling> (last visited Oct 19, 2017).

[2] Alex Avard, A, Video games have a loot box fetish, and it's starting to harm the way we play. GAMES RADAR October 10 (2017) <http://www.gamesradar.com/loot-boxes-shadow-ofwar/> (last visited Oct 19, 2017).

[3] Wikipedia, Loot box (2017) <https://en.wikipedia.org/wiki/Loot_box> (last visited Oct 19, 2017).

[4] Mark D. Griffiths, ADOLESCENT GAMBLING (1995).

[5] Mark D. Griffiths and Rosie King, Are mini-games within RuneScape gambling or gaming? 19 GAMING LAW REVIEW AND ECONOMICS. 64-643 (2015)

[6] Mark D. Griffiths and Margaret Carran, Are online penny auctions a form of gambling? 19 GAMING LAW REVIEW AND ECONOMICS. 190-196 (2015)

[7] Gambling Commission, VIRTUAL CURRENCIES, ESPORTS AND SOCIAL CASINO GAMING - POSITION PAPER. Gambling Commission (2017) 
[8] Heather Alexandra, Loot boxes are designed to exploit us. KOTAKU October 13 (2017) <https://kotaku.com/loot-boxes-are-designed-to-exploit-us-1819457592> (last visited Oct 19, 2017).

[9] Nathan Lawrence, N, The troubling psychology of pay-to-loot systems. IGN, April 23 (2017) <http:/ /uk.ign.com/articles/2017/04/24/the-troubling-psychology-of-pay-to-loot-systems> (last visited Oct 19, 2017).

[10] Matthew Perks, Limited edition loot boxes: Problematic gambling and monetization. CUBE October 11 (2016) <https://medium.com/the-cube/limited-edition-loot-boxes-problematicgambling-and-monetization-756819f2c54f > (last visited Oct 19, 2017).

[11] Alex Wiltshire, Behind the addictive psychology and seductive art of loot boxes. PC GAMER September 29 (2017) <http://www.pcgamer.com/behind-the-addictive-psychologyand-seductive-art-of-loot-boxes/> (last visited Oct 19, 2017).

[12] Mark D. Griffiths, Adolescent gambling and gambling-type games on social networking sites: Issues, concerns, and recommendations. 33(2) ALOMA: REVISTA DE PSICOLOGIA, CIÈNCIES DE L'EDUCACIÓ I DE L'ESPORT. 31-37 (2015) 